\title{
Transmission, Other/Miscellaneous
}

National Cancer Institute

\section{Source}

National Cancer Institute. Transmission, Other/Miscellaneous. NCI Thesaurus. Code C19083.

Passage or transfer, as of a disease, to a recipient individual due to miscellaneous or not otherwise specified circumstances. ( $\mathrm{NCl})$ 